\title{
Minireview
}

\section{Cryopreservation of bovine oocytes: Current status and recent developments}

\author{
Alban MASSIP* \\ Université catholique de Louvain, Institut des Sciences de la Vie, \\ Unité des Sciences vétérinaires, Place Croix du Sud 5 Bte 10, 1348 Louvain-la-Neuve, Belgium
}

(Received 22 November 2002; accepted 17 June 2003)

\begin{abstract}
The cryopreservation of oocytes of most animal species remains a challenge due to their complex structure. Equilibrium freezing is not satisfactory because oocytes seem to be damaged by exposure for several minutes to temperatures near $0{ }^{\circ} \mathrm{C}$. Therefore, cryopreservation of oocytes by vitrification - especially the use of very high cooling rates of oocytes suspended in extremely small volumes of various cryoprotective additive modifications - seems the most appropriate method.
\end{abstract}

oocyte / bovine / cryopreservation

The cryopreservation of bovine oocytes remains a challenge despite significant recently reported progress $[1,2]$. Conventional as well as vitrification methods have been applied to immature and mature oocytes and very few calves have been born following the transfer of blastocysts derived from frozen or vitrified oocytes [2-7]. The factors affecting the cryopreservation of mammalian oocytes have been reviewed [2-9]. Since there is a growing interest in the possibility of obtaining blastocysts from cryopreserved oocytes for the application to new technologies, research on cryopreservation of oocytes has become a priority.

In this paper, I examined the reasons for this poor success rate at different levels and how it might be improved. Reviews on the cryobiology of mammalian oocytes have been published $[8,10,11]$.

\section{PROBLEMS CURRENTLY ASSOCIATED WITH CRYOPRESERVATION OF BOVINE OOCYTES}

\subsection{Source of oocytes}

Experiments on cloning and transgenesis need a lot of oocytes and if they could be stored frozen this would be very interesting from a logistical point of view [12]. The main source of oocytes is from abattoir ovaries then ovum pick up. Abattoir material is very heterogenous because oocytes

\footnotetext{
* Deceased on 4th July 2003.

Corresponding author: Isabelle Donnay: donnay@ vete.ucl.ac.be
} 
are punctured from follicles of different sizes and we know that the ability of oocytes to complete all stages of development and probably also to support freezing is related to follicle size [13] and consequently to the size of the oocyte [14]. So, not only the mixed origin but also the fact that the subsequent maturation is performed in vitro means a compromised situation compared with in vivo maturation.

\subsection{Stage of maturation}

The oocyte is a unique and large cell with a low surface area volume ratio, surrounded by a zona pellucida (ZP) and several layers of granulosa cells forming the cumulus oocyte complex (COC). The cells immediately adjacent to the oocyte, the corona radiata cells, have long cytoplasmic extensions which penetrate the ZP and terminate in bulbous swellings closely associated with the oocyte membrane. The presence of these processes and of gap junctions play an important role in the metabolic cooperation between oocyte and cumulus cells during the growth phase of the oocyte [15].

When oocytes are aspirated from follicles on ovaries derived from an abattoir, they are at the GV (Germinal Vesicle) stage of maturation. An important characteristic of the GV stage oocyte is that the genetic material is contained at early prophase within the contours of a nucleus. Since no spindle is present, this type of oocyte is assumed to be less prone to microtubular and chromosomal damage. However, progress in the cryopreservation of $\mathrm{GV}$ bovine oocytes has been limited and only two papers report the production of offspring derived from them $[5,6]$.

The other stage that is traditionally cryopreserved is the mature oocyte at the metaphase II stage of maturation. The cumulus surrounding the oocyte is expanded and cell cohesion is maintained by hyaluronic acid. A series of cytoskeletal elements play an active role during the maturation process of the oocyte. For example microfilaments of actin are involved in cell shape modifications and movements and microtubules form the spindle apparatus [8].

Exposing oocytes to cryoprotective additives (CPAs) and/or cooling them from about $37{ }^{\circ} \mathrm{C}$ to $20{ }^{\circ} \mathrm{C}$ or below causes various cytoskeletal and chromosomal alterations. Nevertheless, calves have been obtained from mature oocytes that have been frozen slowly $[3,5,16,17]$ as well as from vitrified ones $[4,7]$. Therefore, whatever the cryoprotectant or the method of cryopreservation, the developmental potential of oocytes frozen at the GV or the MII stage appears to be quite similar [17].

Although mature and immature oocytes have been cryopreserved, cooling GV oocytes to $4{ }^{\circ} \mathrm{C}$ or $0{ }^{\circ} \mathrm{C}$ reduces the formation of normal meiotic spindles [18] and of fertilization. Cryoprotectants and exposure of mature oocytes to low temperatures can cause chromosome dispersal, microtubule depolymerisation $[19,20]$. There are also changes in the composition and permeability of the plasma membrane during maturation. The permeability of bovine oocytes to water and to cryoprotectants changes after in vitro maturation [21]. Furthermore, the permeability of bovine oocytes to DMSO is higher than that to ethylene glycol. The maturation stage has a significant influence on the developmental competence of oocytes after cryopreservation. This was observed [22-25] when oocytes were cryopreserved at different times of the maturation process; various meiotic stages exhibit different sensitivities to cooling. Maturation protocols also affect an oocyte's ability to tolerate cryopreservation $[25,26]$. It should be noted that DNA may be damaged by cryopreservation whatever the method used [27].

\subsection{Cumulus cell investment}

Cumulus and granulosa cells are necessary to provide the oocyte with nutritive 
substances and may have a supportive role at fertilization in vitro. The multiple roles of the cumulus oophorus have been reviewed $[15,28]$. These cells may be an obstacle to the penetration of cryoprotectants [29] or the gap junctions can be altered by cryopreservation.

\subsection{Osmotic stress}

It has been shown that exposure to anisotonic conditions has a significant effect on the developmental competence of bovine MII COC at both the GV and MII stages. Oocytes at the GV stage are more sensitive to anisotonic stress than MII oocytes [30]. High concentrations of sodium are detrimental to mouse embryos during freezing [31].

\subsection{Chilling sensitivity}

In bovine oocytes, low temperature sensitivity is attributed to two different factors. Besides damage of the numerous lipid droplets, the meiotic spindle of the metaphase II oocyte suffers serious injury when cooled to 4 or even $25^{\circ} \mathrm{C}[1,19]$. Unlike the lipid alteration, damage to the spindle after short-time low-temperature exposure is reversible, but even so may disturb the subsequent fertilization process.

\section{HOW TO IMPROVE OOCYTE CRYOPRESERVATION?}

The following possibilities should be considered to achieve higher blastocyst rates and healthy offspring after fertilization of cryopreserved bovine oocytes:

(1) Cryopreserve only competent oocytes, preferably those that have been ovulated. To my knowledge, nobody has tried to freeze oocytes matured in vivo in the cow. Oocytes that are competent to develop to term are probably also more resistant to freezing. It has been demonstrated that the blastocyst yield is significantly higher when oocytes are matured in vivo compared with in vitro [32]. Another study [33] comparing in vitro with in vivo maturation made it clear that the developmental potential of in vitro matured oocytes is generally lower than that of in vivo matured oocytes.

(2) Cryopreserve oocytes from large follicles that have reached the diameter at which they are considered competent. There is evidence that oocytes collected in the presence of a dominant follicle are of lesser quality than those collected during follicular growth [34, 35].

(3) Culture oocytes during arrested meiosis to improve their developmental competence after fertilization [36, 37]. Multiple attempts have been made with various inhibitors, the aim being to allow the oocyte to accumulate sufficient material to support development. Recently, two compounds, butyrolactone and roscovitine were tested separately or together [38, 39]. Calves have been born after such treatments (our unpublished observations). Apparently, cryopreservation of such premature oocytes has not been attempted.

(4) Partially remove the cumulus cell investments several hours after the start of the in vitro maturation. This step may facilitate cryoprotectant penetration while maintaining the supportive role of these cell layers in the subsequent final maturation, fertilization and also further development [40].

(5) The permeating component(s) of the cryoprotectant mixture should penetrate bovine oocytes rapidly so as to minimise osmotic shock and also to ensure appropriate protection for the whole cell. Ethylene glycol, propylene glycol and dimethylsulphoxide seem to be the best candidates.

(6) Cryopreservation of oocytes after centrifugation to eliminate cytoplasmic lipid droplets partially responsible for chilling sensitivity. Attempts undertaken were not conclusive [41]. The polarization of cytoplasmic lipid droplets had a negative effect on the survival of frozen thawed 
oocytes. Thus this treatment did not improve the frequency of normal fertilization and development to blastocysts, compared with that of frozen control oocytes. However the frequency of polyspermy of those surviving freezing-thawing was less than those of surviving control oocytes.

(7) Another and probably more efficient approach to avoid chilling injury is to increase the cooling rate through the dangerous temperature zone (between +15 and $-15)$. There are several methods; one of them is the solid-surface vitrification where oocytes are vitrified in microdrops on a precooled metal surface [12]. Cryopreservation of oocytes in $0.25 \mathrm{~mL}$ straws immersed directly into liquid nitrogen versus those placed on top of very small microscope grids to cool them very rapidly showed that $15 \%$ of the latter developed into blastocysts after fertilization and culture [42]. This was interpreted as being due to small size and the very high cooling rate achieved with the grids. The open-pulled straw (OPS) method consisting in pulling a conventional $0.25 \mathrm{~mL}$ straw to half of its diameter and wall thickness so that a very small volume of vitrification medium is aspirated by capillarity with oocytes [40]. Another method is to create a thin film of cryoprotectant solution in a small nylon loop [43]. Cryoloop vitrification was compared to the OPS method and with in vitro matured oocytes, $33 \%$ of those fertilized continued development to the morula/ blastocyst stage $(n=42)$. These new high speed vitrification methods dramatically decrease the chilling injury, permit the use of less concentrated and less toxic solutions and shorten the time of exposure with the final cryoprotectant both before cooling and after warming. High rates of survival have been obtained using a new cryoloop vitrification technique followed by ICSI [44]. Additionally, the small volume of the solution prevents heterogeneous ice formation [45]. Finally, the use of liposomes may alter chilling sensitivity of bovine oocytes [46].
Consequently, a considerable advance in the cryopreservation of certain mammalian ova and embryos has been achieved. These results have generated a search for new methods for further increasing the cooling rates $[43,44]$.

\section{CONCLUSION}

The cryopreservation of mammalian oocytes remains a challenge in most animal species due to its complex structure. Equilibrium freezing is not satisfactory and it seems that in this special case vitrification is the most appropriate method.

The ways indicated in this brief review to cryopreserve this special cell, the oocyte, are the existing ways but perhaps there are other possibilities by exploring for example the reasons why it can be arrested for several decades before resuming meiosis. Cryopreservation of primordial follicles is also a new although a complicated way [47].

\section{ACKNOWLEDGEMENTS}

This work was supported by EU grant "Ex Ovo Omnia", Contract No. QLK3- CT199900104. I thank Dr Stanley P. Leibo for reading of the manuscript.

\section{REFERENCES}

[1] Martino A, Pollard JW, Leibo SP. Effect of Chilling Bovine Oocytes on Their Developmental Competence. Mol Reprod Dev 1996, 45: 503-512.

[2] Vajta G, Holm P, Kuwayama M, Booth P, Jacobsen H, Greve T, Callesen H. Open Pulled Straw (OPS) Vitrification: A New Way to Reduce Cryoinjuries of Bovine Ova and Embryos. Mol Reprod Dev 1998, 51: 53-58.

[3] Fuku E, Kojima T, Shioya Y, Marcus GJ, Downey BR. In vitro fertilization and development of frozen-thawed bovine oocytes. Cryobiology 1992, 29: 485-492.

[4] Hamano S, Koikeda A, Kuwayama M, Nagai T. Full term development of in vitro matured, 
vitrified, and fertilized bovine oocytes. Theriogenology 1992, 38: 1085-1090.

[5] Otoi T, Yamamoto K, Koyama N, Suzuki T. In Vitro Fertilization and Development of Immature and Mature Bovine Oocytes Cryopreserved by Ethylene Glycol with Sucrose. Cryobiology 1995, 32: 455-460.

[6] Suzuki T, Boediono A, Takagi M, Saha S, Sumantri C. Fertilization and Development of Frozen-Thawed Germinal Vesicle Bovine Oocytes by a One-Step Dilution Method In Vitro. Cryobiology 1996, 33: 515-524.

[7] Le Gal F, De Roover R, Verhaeghe B, Etienne D, Massip A. Development of vitrified matured cattle oocytes after thawing and culture in vitro. Vet Rec 2000, 146: 469-471.

[8] Parks JE, Ruffing NA. Factors affecting low temperature survival of mammalian oocytes. Theriogenology 1992, 37: 59-75.

[9] Papis K, Shimizu M, Izaike Y. Factors affecting the survivability of bovine oocytes vitrified in droplets. Theriogenology 2000, 54: 651-658.

[10] Critser JK, Agca Y, Gunasena KT. The cryobiology of mammalian oocyte. In: Karow AM, Critser JK (Eds), Reproductive tissue banking, Academic Press, 1994. p 329-351.

[11] Ledda S, Leoni G, Bogliolo L, Naitana S. Oocyte cryopreservation and ovarian tissue banking. Theriogenology 2001, 55: 1359-1371.

[12] Dinnyes A, Dai Y, Jiang S, Yang X. High developmental rates of vitrified bovine oocytes following parthenogenetic activation, in vitro fertilization, and somatic cell nuclear transfer. Biol Reprod 2000, 63: 513-518.

[13] Lonergan P, Monaghan P, Rizos D, Boland MP, Gordon I. Effect of follicle size on bovine oocyte quality and developmental competence following maturation, fertilization and culture in vitro. Mol Reprod Dev 1994, 37: 48-53.

[14] Fair T, Hyttel P, Greve T. Bovine oocyte diameter in relation to maturational competence and transcriptional activity. Mol Reprod Dev 1995, 42: 437-442.

[15] Van Soom A, Tanghe S, De Pauw I, Maes D, De Kruif A. Function of the cumulus oophorus before and during mammalian fertilization. Reprod Dom Anim 2002, 37: 144-151.

[16] Otoi T, Tachikawa S, Kondo S, Suzuki T. Developmental capacity of bovine oocytes frozen in different cryoprotectants. Theriogenology 1993, 40: 801-807.

[17] Kubota C, Yang X, Dinnyes A, Todoroki J, Yamakuchi H, Mizoshita K, Inohae S, Tabara N. In vitro and in vivo survival of frozen-thawed bovine oocytes after IVF, nuclear transfer, and parthenogenetic activation. Mol Reprod Dev 1998, 51: 281-286.
[18] Wu B, Tong J, Leibo SP. Effects of Cooling Germinal Vesicle-Stage Bovine Oocytes on Meiotic Spindle Formation Following In Vitro Maturation. Mol Reprod Dev 1999, 54: 388-395.

[19] Aman RR, Parks JE. Effects of cooling and rewarming on the meiotic spindle and chromosomes of in vitro-matured bovine oocytes. Biol Reprod 1994, 50: 103-110.

[20] Saunders KM, Parks JE. Effects of Cryopreservation Procedures on the Cytology and Fertilization Rate of In Vitro-Matured Bovine Oocytes. Biol Reprod 1999, 61: 178-187.

[21] Agca Y, Liu J, Peter AT, Critser ES, Critser JK. Effect of developmental stage on bovine oocyte plasma membrane water and cryoprotectant permeability characteristics. Mol Reprod Dev 1998, 49: 408-415.

[22] Lim JM, Fukui Y, Ono H. Developmental competence of bovine oocytes frozen at various maturation stages followed by in vitro maturation and fertilization. Theriogenology 1992, 37: 351-361.

[23] Im KS, Kang JK, Kim HS. Effects of cumulus cells, different cryoprotectants, various maturation stages and preincubation before insemination on developmental capacity of frozen-thawed bovine oocytes. Theriogenology 1997, 47: 881-891.

[24] Hochi S, Ito K, Hirabayashi M, Ueda M, Kimura K, Hanada A. Effect of nuclear stages during IVM on the survival of vitrified-warmed bovine oocytes. Theriogenology 1998, 49: 787-796.

[25] Luna HS, Ferrari I, Rumpf R. Influence of stage of maturation of bovine oocytes at time of vitrification on the incidence of diploid metaphase II at completion of maturation. Anim Reprod Sci 2001, 68: 23-28.

[26] Men H, Monson RL, Rutledge JJ. Effect of meiotic stages and maturation protocols on bovine oocyte's resistance to cryopreservation. Theriogenology 2002, 57: 1095-1103.

[27] Men H, Monson RL, Parrish JJ, Rutledge JJ. Detection of DNA damage in bovine metaphase II oocytes resulting from cryopreservation. Mol Reprod Dev 2003, 64: 245-250.

[28] Tanghe S, Van Soom A, Nauwynck H, Coryn M, De Kruif A. Functions of the cumulus oophorus during oocyte maturation, ovulation, and fertilization. Mol Reprod Dev 2002, 61: 414-424.

[29] Vajta G. Vitrification of the oocytes and embryos of domestic animals. Anim Reprod Sci 2000, 60-61: 357-364.

[30] Agca Y, Liu J, Rutledge JJ, Critser ES, Critser JK. Effect of osmotic stress on the developmental competence of germinal vesicle and metaphase II stage bovine cumulus oocyte complexes and its relevance to cryopreservation. Mol Reprod Dev 2000, 55: 212-219. 
[31] Stachecky JJ, Cohen J, Willadsen S. Detrimental effects of sodium during mouse oocyte cryopreservation. Biol Reprod 1998, 59: 395-400.

[32] Van Soom A, de Kruif A. A comparative study of in vivo and in vitro derived bovine embryos. Proc 12th Int Congr Anim Reprod 1992, 3: 1365-1367.

[33] Rizos D, Ward F, Duffy P, Boland MP, Lonergan P. Consequences of bovine oocyte maturation, fertilization or early embryo development in vitro versus in vivo: implications for blastocyst yield and blastocyst quality. Mol Reprod Dev 2002, 61: 234-248.

[34] Garcia A, Salahedine M. Effects of repeated ultrasound-guided transvaginal follicular aspiration on bovine oocyte recovery and subsequent follicular development. Theriogenology 1998, 50: 575-585.

[35] Hagemann LJ, Beaumont SE, Berg M, Donisson MJ, Ledgard A, Pererson AJ. Development during IVP of bovine oocytes from dissected follicles: interactive effects of estrous cycle stage, follicle size and atresia. Mol Reprod Dev 1999, 53: 451-458.

[36] Duranthon V, Renard JP. The developmental competence of mammalian oocytes: a convenient but biologically fuzzy concept. Theriogenology 2001, 55: 1277-1289.

[37] Sirard MA. Resumption of meiosis: mechanism involved in meiotic progression and its relation with developmental competence. Theriogenology 2001, 55: 1241-1254.

[38] Mermillod P, Tomanek M, Marchal R, Meijer L. High developmental competence of cattle oocytes maintained at the Germinal Vesicle Stage for 24 hours in culture by specific inhibition of MPF kinase activity. Mol Reprod Dev 2000, 55: 89-95.
[39] Hashimoto S, Minami N, Takakura R, Imai H Bovine immature oocytes acquire developmental competence during meiotic arrest in vitro. Biol Reprod 2002, 66: 1696-1701.

[40] Vajta G, Booth PJ, Holm P, Greve T, Callesen H. Successful vitrification of early stage bovine in vitro produced embryos with the Open Pulled Straw Method (OPS). Cryo-Letters 1997, 18: 191-195.

[41] Otoi T, Yamamoto K, Koyama N, Tachikawa S, Murakami M, Kikkawa Y, Suzuki T. Cryopreservation of Mature Bovine Oocytes Following Centrifugation Treatment. Cryobiology 1997, 34: $36-41$

[42] Martino A, Songsasen N, Leibo SP. Development into Blastocysts of Bovine Oocytes Cryopreserved by Ultra-Rapid Cooling. Biol Reprod 1996, 54: 1059-1069.

[43] Lane M, Bavister BD, Lyons EA, Forest KT. Containerless vitrification of mammalian oocytes and embryos. Nat Biotechnol 1999, 17: 1234-1236.

[44] Mavrides A, Morroll D. Cryopreservation of bovine oocytes: is cryoloop vitrification the future to preserving the female gamete? Reprod Nutr Dev 2002, 42: 73-80.

[45] Rall WF. Factors affecting the survival of mouse embryos cryopreserved by vitrification. Cryobiology 1987, 24: 387-402.

[46] Zeron Y, Tomczak M, Crowe J, Arav A. The effect of liposomes on thermotropic membrane phase transition of bovine spermatozoa and oocytes: implications for reducing chilling sensitivity. Cryobiology 2002, 45: 143-152.

[47] Gosden RG, Mullan J, Picton HM, Yin H, Tan SL. Current perspective on primordial follicle cryopreservation and culture for reproductive medicine. Human Reprod Update 2002, 8: 105-110. 